\title{
Remote Sensing Applications for Sustainable Aquaculture in Africa
}

\author{
Joseph E. Quansah ${ }^{1}$, Gilbert L. Rochon ${ }^{2}$, Kwamena K. \\ Quagrainie $^{3}$ \\ 1 Purdue University, Dept. of Agricultural \& Biological \\ Engineering, West Lafayette, Indiana, USA \\ jquansah@purdue.edu \\ ${ }^{2}$ Purdue University, Purdue Terrestrial Observatory, Rosen \\ Center for Advanced Computing, Information Technology \\ at Purdue, West Lafayette, Indiana, USA \\ rochon@purdue.edu \\ ${ }^{3}$ Purdue University, Dept. of Agricultural Economics, West \\ Lafayette, Indiana, USA \\ kquagrai@purdue.edu
}

\begin{abstract}
The authors review the current state of the science with respect to remote sensing applications for aquaculture, including site location, aquaculture facility mapping, market proximity analysis and associated roadway infrastructure, epizootic mitigation, meteorological event and flood early warning, environmental pollution monitoring, and aquatic ecosystem impact, primarily for catfish (Clarias spp.) and tilapia (Tilapia spp.; Oreochromis spp.), inter alia. The potential of technology transfer from the controlled environment aquaculture research facilities at Purdue University, West Lafayette, Indiana, USA to partnering institutions in Ghana and Kenya are explored. The potential for multi-sensor remote sensing deployment to support sustainable fish production in these environments and subsequently in other African countries is evaluated.
\end{abstract}

Keywords:Aquaculture, Remote Sensing, Water Quality, Africa

\section{Introduction:}

Despite the relative abundance and variety of fish in the Red Sea and Mediterranean Sea, bordering ancient Egypt, as well as in the traversing Nile River [1], there is some indication that Egyptian aquaculture may date back to 2500 BC, according to Basurco \& Lovatelli [2], based upon drawings on the tomb of Aktihep. Archaeological evidence of fishing activity, per se, in sub-Saharan Africa has been suggested from artifacts, dating as far back as the Middle Stone Age. As reported by Henshilwood \& Sealy [3], "Here we examine new evidence from Blombos Cave [South Africa] indicating that by at least 40,000 years ago MSA [Middle Stone Age] people at this site were making bone artifacts, scoring bone with possible symbolic connotations, and fishing."

\author{
Steve Amisah ${ }^{4}$, Mucai Muchiri ${ }^{5}$, Charles Ngugi ${ }^{5}$ \\ ${ }^{4}$ University of Science \& Technology, Kumasi, Ghana \\ steveamisah1@yahoo.co.uk \\ ${ }^{5}$ Moi University, Eldoret, Kenya \\ cngugi@africaonline.co.ke \\ muchirim@africoonline.co.ke
}

Contact: rochon@purdue.edu

Research on contemporary fish farming-related issues within the African continent addresses diverse areas of concentration, including the deleterious impact of the aquaculture industry and human population growth on coastal lagoons in Egypt [4], trend extrapolation and future sustainability of aquaculture in Egypt, Libya, Algeria, Tunisia and Morocco [2], the potential and constraints associated with economic sustainability of traditional and commercial African aquaculture in Egypt, Nigeria, Zambia and Madagascar [5], ecosystem resilience, sustainable coastal management and human impact on mangroves in Africa, Asia \& Latin America and the utility of remote sensing (i.e. SPOT) for mangrove conservation and management in Madagascar [6].

\section{Aquaculture in Africa:}

Fish has always been an important part of the diet of Africans; but until recently, fish has been largely harvested from the wild. Total fish output in African nations, such as in Nigeria and Egypt, continues to grow at accelerating rates as aquaculture (fish cultivation) has become part of many rural agricultural enterprises. This has been encouraged by expansions of NGO developmental activities in aquaculture, improved aquaculture production technologies, recognition of over exploitation of natural fisheries, decline in natural and environmental resources, and increased nutritional requirements of rapidly growing populations. These factors combine to make aquaculture an economically attractive agricultural production alternative in sub-Saharan Africa. Aquaculture provides economic opportunities, which include contribution to food security and poverty alleviation through employment and income generation.

The scale of individual aquaculture operations in most subSaharan African countries is small because many rural farmers have small land holdings; nevertheless the industry as a whole is growing. The culture method is predominantly dug out earthen ponds for the culture of tilapia, the most commonly 
cultured fish. Water sources for fish production are creeks and streams, and to some extent, natural rain water. In Africa, there are more than 100 species of tilapia of which less than 10 are cultured. Of these, the Nile tilapia Oreochromis niloticus is the most popular followed by O. mossambicus. The African catfish, Clarias gariepinus, is also endemic to lakes in the region and popular among communities living around these lakes. Catfish are commonly farmed in polyculture with Nile tilapia to control unwanted tilapia populations. Catfish are also produced as food fish from monoculture.

Economic studies have demonstrated that fish farming is a viable enterprise for African producers with high gains, but minimum costs $[7 ; 8 ; 9]$. In particular, Engle et al. [8] reported that fish production in Rwanda represented the main cash crop for over 50 percent of farmers and private pond holders. Large-scale intensive enterprises have proven to be beyond the means of farmers and many African governments and studies have indicated that smallholder commercial farmers are profitable economic activities [10]. In Kenya, technology transfer through participation in non-governmental aquaculture developmental activities, such as USAID Aquaculture Collaborative Research Support Programs, has resulted in significant improvements in Kenyan production of farmed fish $[11 ; 12]$. The successes of small-scale aquaculture are attracting investment into the industry in Kenya.

The growth of aquaculture in Africa is attracting concerns relating to the environmental impact. Aquaculture as an industry is unique in the sense of being a potential polluter of natural water bodies with effluents and a user of polluted water. Aquaculture in rural Africa is linked with natural ecosystems and could have a profound impact on aquatic environmental quality. The main components of aquaculture waste water include nutrients (e.g. nitrogen and phosphorus), biochemical oxygen demand, suspended solids, and pathogens [13]. Additions of nitrogen and phosphorus to natural waters can cause eutrophication. Effluent discharges from aquaculture operations could have high concentrations of settleable solids and other organic suspended solids in the form of plankton, which end up in natural water bodies. Natural organic fertilizers are commonly used in fish ponds to generate heavy blooms of algae. For example, a test of a sample of 11 common feeds and four organic fertilizers used in Ghana indicated three of the feeds (i.e. biscuit waste, groundnut husk, and dried termite) and three of the organic fertilizers (i.e. cow manure, pig manure, and poultry manure) contained significant counts of faecal coliforms [14]. Additionally, four out of 11 feeds (i.e. biscuit waste, cassava, groundnut husk, and termites) and all organic fertilizers (i.e. poultry manure, cow manure, pig manure, and cow blood) contained fecal streptococci [15]. These and many pathogens may be passed on in effluents to receiving waters.

\section{Remote Sensing Applications for Aquaculture:}

Acoustic techniques for estimating fish abundance initially served as precursors for satellite remote sensing and have been operational for at least the past thirty-five years [15]. Moreover, "sonar echo statistics" have been deployed for estimating fish school density and classification of fish and rough seafloor "by analyzing the nature of echo fluctuations" [16]. More recently, Fisher et al. [17] reported on tracking fish with microwatt acoustical receivers.

NASA Stennis Space Center's Lear Jet-mounted Calibrated Airborne Multispectral Scanner (CAMS) has been utilized to monitor turbid finfish aquaculture impoundments in Mississippi [18]. Unmanned radar installations have also been used in Canada to support an "integrated maritime surveillance system" for protecting the Canadian 200nm exclusive economic zone and for monitoring not only illicit fish poaching but also drug trafficking, smuggling, piracy and illegal immigration [19]. The potential of transferring such surveillance technologies to Africa has been largely unexplored. While not as broad spectrum in their design and scope as the Canadian initiative, other countries have combined remote sensing with Geographic Information Systems (GIS), for example, in Viet Nam, to address sustainable management of coastal zones [20] and of watershed ponds for aquaculture [21], of shrimp culture in India [22], spatial and temporal change detection in Taiwan [23], crab and shrimp aquaculture in Bangladesh [24] and coastal reclamation and management in Thailand, [25] in response to the impact of near-shore marine shrimp aquaculture and other human activities.

Within Africa, Rasolofoharinoro et al. [6] have conducted field surveys for mangrove mapping in Madagascar, in combination with analysis of data from the French Space Agency (CNES) SPOT 1 and SPOT2 satellites. Of particular concern is the disproportionate impact of climate change on both agriculture and aquaculture in the developing countries, with profound implications for food security and poverty alleviation. The role of remote sensing in predicting decreased fish catch in the world's oceans, given impending increase in water temperature has been investigated [26] as has the role of remote sensing in support of Kyoto Protocol compliance [27] .

During the Cold War, the United States and Russia dominated earth observing satellite capabilities. Thirteen countries now have their own earth observing sensors in orbit and twenty countries are projected to have such assets by 2010, according to Stoney [28]. In Africa, Nigeria, South Africa, Tunisia and Algeria all have orbiting satellites and Morocco will soon join the group. In addition, universities, government research laboratories and, to a lesser extent, some private sector firms throughout the African continent, from Egypt to Madagascar, have laboratories equipped for analysis of remotely sensed data for instruction, research and applications development. Ground stations in South Africa have the capability to ingest real-time satellite data from a wide array of American, European, Canadian, Indian and Chinese satellites. In late 2007, South Africa in collaboration with Belgium plans to launch a hyperspectral satellite, Microsatellite Multi-Spectral Imager (MSMI) that has the potential to enable species-specific botanical differentiation and thereby greatly upgrade capacity to identify suitable locations for sustainable aquaculture development. One key variable in aquaculture siting and sustainable fisheries development within Africa and globally is water quality. For such suitability determinations, satellite data alone is frequently insufficient and optimally serves as but one 
component of a spatial database, also incorporating in situ data and socio-economic data.

\section{Case Study - Ghana: Monitoring Water Quality of the Lower Volta Using a GIS Approach:}

The Volta basin is one of Ghana's most important assets that drive the country's economy. The river is dammed at Kpong and Akosombo and forms the focus of supply of electricity to the country and some neighboring African countries, such as Togo and Benin. Increasing anthropogenic activities such as fishing, aquaculture, agriculture, industries and urban development around the river have resulted in various point and non-point source pollution to the river, impacting the water quality considerably over the years. The Volta River Authority has tried to monitor the water quality of the basin but their efforts have been constrained by the massive size of the basin and the lack of suitable technology to keep pace with developing trends in pollution of the lake waters. Geographic Information Systems (GIS) and Remote Sensing techniques represent important tools that can be used to rapidly assess water quality measurements, create a database, integrate information, visualize scenarios and solve complex problems of environmental pollution. It is against this background that this study was carried out with the following objectives:

- $\quad$ To establish a trend in water quality changes along the Volta River using GIS approach

- To create a database of water quality parameters at specific points along the Volta for depicting trends

- To facilitate future updates to the database

Seven sampling points along the Lower Volta in Ghana were chosen for assessment and monitoring for some water quality parameters. The $1^{\text {st }}$ sampling point was 200 meters above the Akosombo effluent outfall. This was to provide a background of the water quality before effluent discharges in lower sections of the lake. The $2^{\text {nd }}$ sampling point for water quality assessment was the Akosombo effluent outfall itself. This point was chosen because this is the point where all waste from Akosombo is emptied into the Volta after some form of pre-treatment. The third sampling point was the shore of the Volta where Akosombo Textiles Limited (ATL) is located. Effluents from the factory impact on the water quality and discharges are known to include Carbonates, Silicates, and Nitrates, Nitrites, Chlorides, Ammonium and phenols. The $4^{\text {th }}$ sampling location had Banana plantations and the water quality is impacted by various agricultural activities associated with commercial production of bananas. Fungicides, fertilizers and manures applied on these farms represent setbacks to water quality. Sampling Point 5 is impacted by artisanal fishing and limited subsistence vegetable and crop farming. Sampling Point six is located below the Kpong Water Treatment Works whilst point sampling point 7 is at the shore of the Volta, where there is a riverside market.

Parameters examined or analyzed from the locations were Temperature, $\mathrm{pH}$, Conductivity, Turbidity, Hardness, TDS, Nitrate, Ammonia, Phosphates, Iron, and Faecal Coliforms.
The computer software used was ESRI's Arc View. A digitized map of the area was made. Water samples were collected from 24 points along the course of the Volta from immediately after the dam to as far as the Kpong GS intake point. This was done every two months throughout the year to monitor water quality changes in the Volta. Seven of these points were chosen for this study. The seven points were digitized onto the map. At each point readings of the various selected water quality parameters were added as attributes by creating fields. A GIS system was set up and the water quality analysis made.

Some effluents were far and above acceptable EPA maximum contaminant levels (MCL), particularly those coming from the Textile industries. The Volta appears to supply considerable dilution for the massive effluents discharged into it but with the increasing impacts this may not be sustained. Traces of fungicides, fertilizers and pesticides were measured and the use of such agricultural chemicals needs to be monitored. There is a need for continued, regular monitoring of the water quality of Volta basin and much effort and assistance is required to achieve this. Training in GIS and Remote Sensing is recommended for staffs of the VRA and EPA, whom are responsible for monitoring the basin.

\section{Purdue Aquaculture Applied Research Expertise:}

Purdue University has a rich history of scientific collaboration with counterparts in Africa, Asia and Latin America. Although such collaboration with respect to aquaculture is in its infancy, some of the potential areas for joint research, distance learning and technology transfer include the following:

Ecotoxicology: Emphases on evaluating sub-lethal effects of contaminants and other environmental stressors on the reproductive physiology of fish and wildlife; development and application of molecular biomarkers of exposure and effects to environmental contaminants; and bioaccumulation rates and factors affecting bioavailability of contaminants in biota.

Fish nutrition: Emphases on evaluating effects of antinutritional factors found in plant-based ingredients on production parameters of commonly reared carnivorous fishes; use of traditional analytical procedures as well as metabolomic and proteomic techniques to determine the effects antinutritional factors have on fish when fed with plant-based ingredients; evaluation of various practical ingredient feed formulations to determine the effects of feeding diets with lower to no fish meal inclusion.

Economics/Marketing: Focus on market analysis, market definition, facilitation of development of distribution and market structures, identification of value-added opportunities for aquaculture products and feeds, and development of farm enterprise budgets.

\section{Remote Sensing Capabilities at Purdue University:}

Remote sensing research and applications at Purdue University originated in the early 1960 s and especially after the creation of the Laboratory of Application of Remote Sensing (LARS) in 1966 by a group of researchers as a 
multidisciplinary research laboratory, involving the School of Agriculture, the School of Science and the Schools of Engineering [29]. The original objectives involved the utilization of remote sensing for various national and international research aimed at developing the fundamental knowledge of the earth and its biophysical processes, as well as the development and improvement of techniques for analyzing and interpreting remotely sensed data, especially in applications directed toward the management of agricultural resources. Over the years, these activities have expanded to include Geographic Information Systems applications [29]. LARS has, since its creation, obtained a substantial archive of data from multiple remote sensing platforms, which is freely available to researchers worldwide for multi-disciplinary environmental investigations. LARS, in collaboration with Purdue University's School of Electrical \& Computer Engineering and faculty from other departments developed the MultiSpec satellite image processing software which has also been placed in the public domain. The LARS program has a state-of-the-art Remote Sensing Laboratory. LARS, in addition to offering courses in remote sensing for graduate students, participates in a joint Masters program in Earth Observation (EO) with the Katholieke Universiteit Leuven, in Belgium.

To expand the remote sensing capabilities and broaden the scope of applications and research, the university has established the Purdue Terrestrial Observatory (PTO). The PTO is a world class real-time multi-satellite remote sensing ground station, capable of receiving synoptic data from multiple panchromatic, multispectral, hyperspectral and radar sensors at a wide range of spatial resolutions, and has the capability to automatically ingest, geo-reference, analyze, archive, and distribute the received data to over nineteen Purdue departments [30;31]. In addition to research partnership with the Schools of Agriculture, Engineering, Liberal Arts, Management, Science, Technology and Veterinary Medicine, the PTO is seeking to expand similar research collaborations with other universities through the NSF supported Extensible Teragrid Facility (ETF). One major aim of the PTO project is to provide near real-time and archival remotely sensed data in support of time-critical multidisciplinary environmental, ecological, agricultural, hydrological, aquaculture, atmospheric and earth science research [30;31]. Moreover, the PTO compliments LARS through the training of students in theory, practical applications, data acquisition and processing data in near-realtime. The PTO will eventually deploy space-based technologies in the service of regional economic development and community engagement [30;31]. Another initiative associated with the PTO is the IndianaView Consortium, an affiliate of the USGS sponsored AmericaView program, which facilitates access to the state-wide archive of satellite data for a collectivity of Indiana-based universities as well as industries and agencies utilizing spatial data [30;31]. The International Rice Research Institute (IRRI) and both the PTO and LARS are developing a collaborative relationship to, inter alia, assess the potential, constraints and best practices for expanding aquaculture integration with rice (Oryza sativa) production in Africa and Asia.
These remote sensing capabilities at Purdue University and on-going institutional collaboration with universities and government ministries in partnering African countries, including South Africa, Sudan, Ethiopia, Nigeria, Ghana, Kenya, Lesotho, Swaziland and Madagascar could be extended to other African countries in the form of technology transfer and research partnerships. Remote sensing related research aimed at improving environmentally-conscious aquaculture production both in the US and Africa could address both fundamental regional food security \& sustainable development concerns.

\section{References}

[1] D. J Brewer, R. F Friedman, "Fish and Fishing in Ancient Egypt" Warminster: Aris \& Phillips, 1989.

[2] B. Basurco and A. Lovatelli, "The Aquaculture Situation In The Mediterranean Sea Predictions For The Future", 2003

[3] C. Henshilwood, J. Sealy, "Bone Artifacts from the Middle Stone Age at Blombos Cave, Southern Cape, South Africa". Current Anthropology, Vol. 38, No. 5 , pp. 890-895, 1997

[4] M. Ahmed, O. E. H. Frihy, and M.A. Yehia, "Environmental Management of the Mediterranean Coastal lagoons of Egypt". Annals of the Geological Survey of Egypt, vol.23, Part 1, pp.491-508, 2001.

[5] D. Jamu and R. Brummett., "Opportunities and challenges for African aquaculture". p. 1-9. In: Gupta, M.V., D.M. Bartley and B.O. Acosta (eds.), Use of genetically improved and alien species for aquaculture and conservation of aquatic biodiversity in Africa. WorldFish Center Conf. Proc. 68, 113p. 2004.

[6] M. Rasolofoharinoro; F. Blasco; M. F. Bellan; M. Aizpuru; T. Gauquelin; J. Denis, "A remote sensing based methodology for mangrove studies in Madagascar". International Journal of Remote

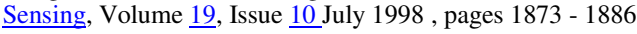

[7] J. J. Molnar, A. Rubagumya, and V. Adjavon, "Sustainability of aquaculture as a farm enterprise in Rwanda". Journal of Applied Aquaculture, 1(2): 37-62, 1991.

[8] C. R. Engle, M. Brewster, and F. Hitayezu. "An economic analysis of fish production in a subsistence agricultural economy: the case of Rwanda." Journal of Aquaculture in the Tropics, 8: 151-165, 1993

[9] C. Lightfoot, M. Perin, and J.K. Ofori "Analytical Framework for Rethinking Aquaculture Development for Smallholder Farmers." In: Research for the future development of aquaculture in Ghana. Editor, M. Perin, J. Ofori, and C. Lightfoot, ICLARM/IAB/GTZ Workshop Accra, Ghana. pp. 4-10. 1996.

[10] U. N. Wijkstrom, and N.J. MacPherson. "A Cost Benefit Analysis of Culture Based Fisheries Development in Small Dams and Dugouts." Field Work Paper 1: The Economics of Culture Based Fisheries. Field Doc. F1:TCP/GHA0051, 7p. FAO, Rome. 1990.

[11] K. L. Veverica, C. Ngugi, J. Amadiva, and J. R. Bowman. "On-Farm Trials: Evaluation of Alternative Aquaculture Technologies by Local Farmers in Kenya, final report In: K. McElwee, K. Lewis, M. Nidiffer, P. Buitrago, D. Clair, J. Burright, S. Sempier and H. Egna (Editors), Nineteenth Annual Technical Report. Pond Dynamics/Aquaculture CRSP, Oregon State University, Corvallis, Oregon, pp 121-133. 2002.

[12] E. Mac'Were, “Comparison of tilapia and Clarias polyculture yields and economic benefits resulting from a locally available animal feed (pig finisher pellet), agricultural by-product (rice bran), and a pelleted test diet in fertilized ponds". M.S. thesis, Moi University, Eldoret, Kenya2002.

[13] S. J. Cripps, and L.A. Kelly. "Reductions in wastes from aquaculture. Pages 166-201 in D.J. Baired, M.C.M. Beveridge, L.A. Kelly, and J.F. Muir. 1996". Aquaculture and water resource management. Blackwell Science, Cambridge, UK ,1996..

[14] J. A. Ampofo, and G.C. Clerk. , "Bacterial flora of fish feeds and organic fertilizers for fish culture ponds in Ghana". Aquaculture Research 34:677-680, 2003. 
[15] J. E. Ehrenberg, D. W. Lytle, “Acoustic Techniques for Estimating Fish Abundance.;Geoscience Electronics, IEEE Transactions on Volume 10, Issue 3, Page(s):138 - 145, July 1972

[16] T. Stanton, C. Clay, "Sonar echo statistics as a remote-sensing tool: Volume and seafloor"Oceanic Engineering, IEEE Journal of Volume 11, Issue 1, Page(s):79 - 96 , Jan 1986

[17] Fisher, Godi, Sangmok Lee, Michael Obara, Prasan Katsuri, H. Thomas Rossby and Conrad W. Reckseik, "Tracking Fishes with a Microwatt Receiver - An Archival Tag Development," IEEE Journal of Oceanic Engineering. 31 (4):975-985. October, 2006.

[18] D. F. Millie, M.C Baker, C. S Tucker, B. T Vinyard, C. P. Dionigi, "High-Resolution Airborne Remote Sensing of Bloom-Forming Phytoplankton" Journal of Phycology JPYLAJ, Vol. 28, No. 3, p 281290, June 1992. 14 fig, 45 ref.

[19] A. M Ponsford,_L. Sevgi, H.C Chan, ,"An integrated maritime surveillance system based on high-frequency surface-wave radars. 2. Operational status and system performance". Raytheon Syst. Canada Ltd., Waterloo, Ont., Canada;This paper appears in: Antennas and Propagation Magazine, IEEE Publication Date: Oct. 2001 Volume: 43 , Issue: 5 On page(s): 52 - 63

[20] Quyen, Nguyen Hanh, Tran Minh Y, Le Thi Thu Hien. "Using Remote Sensing for Coastal Zone Management in Halong Bay (Vietnam)". International Symposium on Geoinformatics for Spatial Infrastructure Development in Earth and Allied Sciences, 2004.

[21] Giap, Dao Huy, Yang Yi, Nguyen Xuan Cuong, Le Thanh Luu, James S. Diana and C. Kwei Lin. "Application of GIS and Remote Sensing for Assessing Watershed Ponds for Aquaculture Development in Thai Nguyen, Vietnam”. Map Asia Conference 2003-Land Use Analysis. GISdevelopment.net

[22] K. Rajitha, C. K. Mukherjee, R. V Chandran, "Applications of remote sensing and GIS for sustainable management of shrimp culture in India “ [Journal Article] Aquacultural Engineering. 2007 Jan. 36(1) p. 1-17. (full text on file)AN: IND43848442
[23] Tsai, Bor-Wen; Kang-Tsung Chang and Chang-Yi Chang. "Analyzing Spatial and Temporal Changes of Aquaculture in Yulin County, Taiwan”. The Professional Geographer, Vol. 58, No. 2 (May, 2006), pp. 161-171, 2006. ISSN 0033-0124

[24] M. A. Salam, G. Lindsay, C. M Ross, M. Beveridge, "A Comparison of Development Opportunities for Crab and Shrimp Aquaculture in Southwestern Bangladesh, using GIS Modeling". Aquaculture, Vol. 220 (2003) pp. 477-494

[25] Flaherty, Mark and Choomjet Karnnjanakesorn. "Marine Shrimp Aquaculture and Natural Resource Management in Thailand, Environmental Management. Vol. 19, No. 1, Jan., 1995, pp. 27-37.

[26] B. K. Biswas, Y. M. Svirezhev, B. K. Bala, "A model to predict climatechange impact on fish catch in the world oceans" Systems, Man and Cybernetics, Part A, IEEE Transactions on. Volume 35, Issue 6, Nov. 2005 Page(s):773 -783

[27] A Rosenquist, A Milne, R Lucas, M Imhoff, C Dobson - "A review of remote sensing technology in support of the Kyoto Protocol - group of 9 Environmental Science \& Policy, 2003 - eorc.jaxa.jp

[28] W. E. Stoney, 2004: ASPRS Guide to Land Imaging Satellites. Updated 10.07.2004, http://www.asprs.org

[29] D. A. Landgrebe, 1986. A Brief History of the Laboratory for Applications of Remote Sensing (LARS) Online source http://www.lars.purdue.edu/home/LARSHistory.html

[30] Gilbert L. Rochon, Loring F. Nies, Chad T. Jafvert, Julie A. Stuart, Rabi H. Mohtar, Joseph Quansah and Akilah Martin. "Education in Sustainable Production in US Universities." Clean Technologies and Environmental Policy. Vol.8, No. 1, pp. 38-48. Springer Verlag (2006).

[31] Gilbert L. Rochon, Chris Johannsen, David Landgrebe, Bernard Engel, Jonathan Harbor, Sarada Majumder and Larry Biehl. "Remote Sensing as a Tool for Achieving and Monitoring Progress Toward Sustainability," Clean Technologies and Environmental Policy, Vol. 5, Nos. 2/3, Springer-Verlag, August, 2003. 